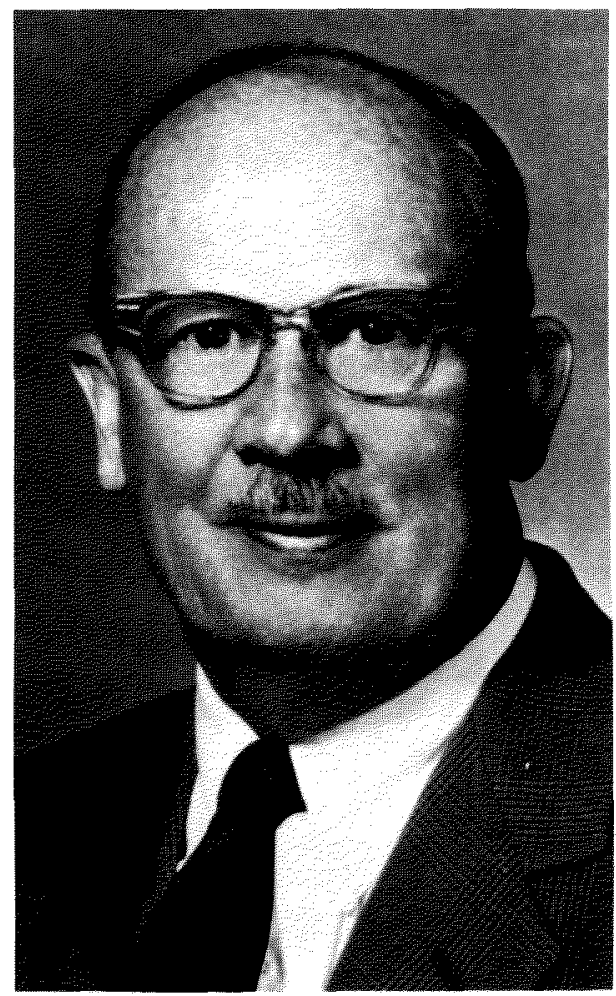

\title{
JACK YOUDEN
}

We are pleased that the Conference proceedings are dedicated to Jack Youden.

Youden, an analytical chemist turned mathematical statistician, was a simplifying and, indeed, enthralling teacher of statistical principles who could hold the attention of sophisticated statisticians as well as scientists and engineers.

Born at the turn of the century, Youden worked for many years at the Boyce Thompson Institute for Plant Research in Yonkers, NY before joining the staff at NBS in 1948. He remained with the Bureau for 17 years and after his retirement continued this association as a guest worker until his death in 1971 .

The transformation of Youden from chemist to statistician probably began with his reading of R. A. Fisher's Statistical Methods for Research Workers. He studied under Fisher in 1937-38 at the Galton Laboratory of University College, London, thanks to a Rockefeller Fellowship for the discovery of a new class of incomplete block designs, "Youden Squares," which found immediate application in biological and medical research.

At NBS he introduced "Youden Plots" for interlaboratory tests and "Youden's Ruggedness Test" as a check on test methods, but he distinguished himself principally for his ability to reduce a complicated idea to its essentials and to express that idea in a simple, straightforward manner, so that it became understandable to scientists of all disciplines. He worked hard at stripping away needless detail and jargon. And he generated interest in his lectures, making his subject so intriguing that an hour passed as minutes. He was a very rare breed-an outstanding statistician who understood experimental systems in chemistry, physics, and engineering.

His first book, Statistical Methods for Chemists, was published in 1951 and was followed by Statistical Techniques for Collaborative Tests which consisted of two 
Youden lecture series, "Accuracy of Analytical Procedures" and "The Collaborative Test." The latter book was published by the Association of Official Analytical Chemists (AOAC) whose William Horwitz states: "These lectures probably have had a greater influence on improving the quality and interpretation of collaborative studies conducted by AOAC members than any other event in the (85-year) existence of the Association."

A number of Youden's most important papers were collected in the Journal of Quality Technology (Vol. 4, No. 1, January 1972) and in Volume 1 of NBS Special Publication 300, Precision Measurement and Calibration: Statistical Concepts and Procedures.

Jack Youden was a chemist and a communicator. The Chemical Division of the American Society for Quality Control in 1969 established a Jack Youden prize to be awarded yearly for the best expository paper in its journal, Technometrics. But it was Youden the statistician who furthered collaboration and helped to maximize the information content of experimentation, which is what the Chemometrics Conference was about. So it is appropriate that these conference proceedings be dedicated to the memory of Dr. Youden.

\section{H. H. Ku}

Statistical Engineering Division
National Bureau of Standards

\section{J. R. DeVoe}

Inorganic Analytical Research Division

National Bureau of Standards 